\title{
Is Alzheimer's Disease an Adaptability Disorder? What Role Does Happiness Have in Treatment, Management and Prevention
}

\author{
John B. Myers \\ Wellspring's Universal Environment P/L, Melbourne, Australia \\ Email: rebdoc1@bigpond.net.au
}

Received 9 April 2015; accepted 30 May 2015; published 2 June 2015

Copyright (C) 2015 by author and Scientific Research Publishing Inc.

This work is licensed under the Creative Commons Attribution International License (CC BY). http://creativecommons.org/licenses/by/4.0/

(c) (7) Open Access

\section{Abstract}

A case presentation indicating the importance of "happiness" in childhood causing memory block until the patent presented with probable mixed vascular and neurodegenerative memory loss at 60 years of age is presented to highlight the role of emotional factors in causing the disease. The question of whether Alzheimer's disease is an adaptability disorder is raised, given the patient blocked out her memory of her childhood experience. The importance of "happiness" as a treatment goal raises issues of advocacy and Guardianship as well as capacity, which is addressed by actual case reference and court action in defence of the patient's rights to have their wishes respected and observed. Functional mental capacity assessment, using the Functional Mental State Measure (FMSM) gives a greater indication of neuronal reserve than standard cognitive testing, as it helps to unravel the dilemma associated with pure cognitive assessment in Alzheimer's Disease as well as vascular dementia patients and patients who, despite retained and intact functional capacity and ability to express their wishes, i.e. "best interest", are "wrongly" placed under Guardianship. Maladaptive responses, to control the change in external environment that are sensed or perceived, and which lead to disorder or to susceptibility to disease, exemplify a General Systems Theory approach, in which appropriate and adequate responses to environmental change, in behavioural terms, by a person, whether independently, or as the recipient or giver, or both, leads to functional interaction and happiness.

\section{Keywords}

Alzheimer's Disease, Vascular Dementia, "Happiness as a Goal, Cause and in Management", Functional Mental Capacity, Memory, Cognitive Development, Advocacy, Behaviour, General Systems Theory 


\section{Aim}

To raise the question of happiness in prevention of Alzheimer's Disease and to guide patient management.

\section{Introduction}

Since the Nun study [1], linguistic ability (as an index of cognitive performance) at base-line has been the focus of attention in terms of development of Alzheimer's Disease though terms of happiness used is found to be associated with longevity [2]. The Scottish tracking study shows that perceived health manifests with less memory impairment and disability in old age [3]. Different factors determine functional reserve including cognitive reserve [4] or neuronal plasticity and vascular factors as well as neuronal regeneration. This indicates that functional reserve which declines with time and which defines aging [5] is determined by initial reserve capacity or brain capacity [4], and by degradation rate over time, though an individual's decline rate may vary depending on the social stressors they encounter. These include nutritional environment, in terms of physical health and mental stimulation as brain "food", and the effects of parental nurturing and socioeconomic factors that may impact to determine physical and mental health and wellbeing, even in old age [6].

The eco-social environment [7] is an important consideration in terms of holistic care and disease prevention. Epigenetic factors and/or familial factors may also play a part in memory development [8] [9], as was suggested in 1982 they do trans-generationally in hypertension development [10]. In terms of General Systems Theory [10], the organism maintains the external milieu in order to function and adapt. Inappropriate and/or inadequate behaviours, by the giver or receiver, leads to disorder or to increased susceptibility of disease in the recipient, being maladaptive responses according to this approach. Functional interaction and happiness is an ideal outcome that reflect adequate and appropriate responses to environmental changes, challenges or stressors, to which the organism, or person, with or without aid, responds.

Study of epigenetic factors as a science has burgeoned since 1990. Various factors have been looked at. Emotional factors may play a part in determining reserve capacity or determine activity of neuronal mechanisms that affect memory, as stress can affect memory or concentration. Chemical drivers or immune responses may be at the core of this [11], or, altered responses of metabolic pathways that remove unwanted memory or limit formation of "good" memory or any of the above may determine the final common pathway through a neurodegenerative process. Whether this is an adaptive phenomenon to either recall "happy" memories or to forget unhappy ones, remains to be determined.

Memory dysfunction in old age may be a mixed disease, due to vascular insufficiency or neurodegenerative effects. Common to both of these may be the effect of emotional "state" or stability. The following case report suggests that this view is an important one that needs to be considered, timing of which may also be critical to determining outcome.

\subsection{Case History}

JF 60 y, married, presented with profound short-term memory loss of several months duration. She expressed that she "has always had 'block-out' memory that helped her to cope with orphanage life from four and a half years of age", which she described as "horrible, frightening, bullying, belting by the nuns-they were brutal. Not all of them". "The more smacks you get the better you'll be. I was as frightened as the children being taunted”. "This has all come up to me recently. I have never spoken about it to this extent, (because of) fear, very much so..."

\subsection{Results}

Normotensive and not diabetic. There was no obvious periodontal disease present [12], though she did mouth breathe [13]. The Folstein Mini-Mental State test score was 21/30 in May, 24/30 on retesting in September that improved with an acetylcholinesterase inhibitor (AChEI) or anti-cholinesterase to MMSE 27/30, with loss of short-term word recall, but feeling better.

The patient's finger nails, Figure 1, shows "nail band width" widening ( $\mathrm{N}$ estimate $<2 \mathrm{~mm}$ ), the nail bed shows terminal recession in an irregular manner and a splinter hemorrhage is noted in the middle finger nail at the proximal edge of the nail band that suggest microvascular involvement in agreement with the micro infarcts seen on brain MRI, Figure 2. Carotid Doppler showed mild plaque. Temporal lobe atrophy, bilateral, was found on MRI, Figure 3. 


\subsection{Discussion}

The patient presented with loss of short term recall which she attributed to "blocking" the memories of an unhappy childhood when from the age of four she was placed in a convent where fear inducing anti-bedwetting codes was used which terrified her.

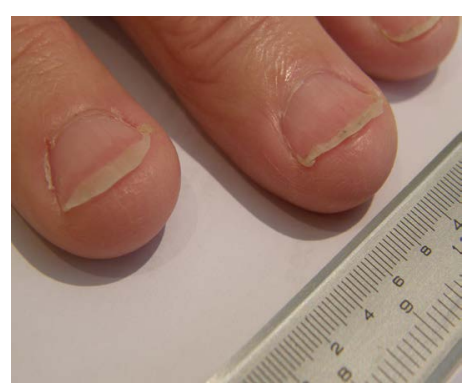

Figure 1. The patient's finger nails show nail band width is widened, the nail bed shows terminal recession in an irregular manner. A pale, receding, splinter hemorrhage is discernible in the middle finger nail bed at the proximal edge of the nail band to the left of centre (lateral side) in line with the 4.4 ruler marking.

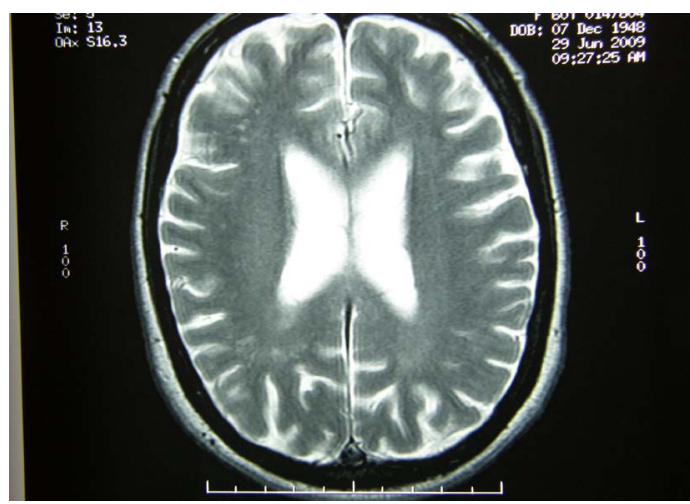

Figure 2. MRI showing micro-infarction in the left subcortical region.

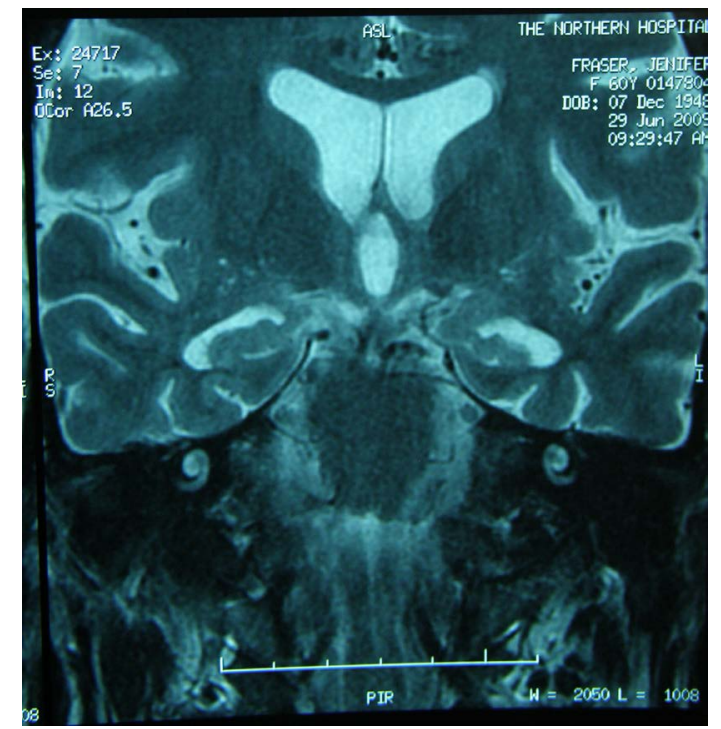

Figure 3. Temporal lobe view of the brain. 
If happiness provides the best milieu for growth and development and learning, then unhappiness may impair this and lead to neurodegenerative and or dementing illness.

The adage "use it or lose it" may occur due to "emotional state" and explain the idea that depression or emotional withdrawal is also associated with cognitive impairment and memory loss while mental stimulation helps to retain it. It is also possible that memory or recall differs in older age. Fernandes showed that when objects were presented to older subjects in a meaningful or recognisable context for them to recall, their results improved and the memory differences between young and older subjects disappeared. It made no difference to recall in the younger group as to whether material presented was in abstract form or in a way that was personal, or familiar and contextual [14]. This raises questions as to the effect of meaning or whether emotional ties influence recall in older age, and whether deep seated connections influence recall in older persons that are not required in younger persons. Similarly, one needs to ask, "is Alzheimer's an adaptability disorder" [15] that impairs memory development even in the young due to "blocking" that leads to temporal lobe atrophy, amyloid deposition and tangles, by removing contextual recall as well as the event, i.e. by removing the emotional component? If so, it behoves us to look as early as childhood, and during fetal development in utero, to determine whether unhappy memories that are blocked leads to temporal lobe atrophy and short-term memory loss, a significant feature of Alzheimer's Disease and whether happy experiences do not [15].

Was Alzheimer's Disease present in this patient? The nail findings and micro-infarctions seen in the subcortical region are more indicative of a vascular picture [5] [16]. However, the response to treatment with an acetylcholinesterase inhibitor, which was tested by Mini-mental Sate examination, could have been spuriously affected and change notwithstanding medical treatment or showed a response expected of a neurodegenerative process rather than a vascular one. In addition to localised subcortical micro infarction, bilateral temporal lobe atrophy, on Brain MRI, was reported. Whichever condition predominates, the patient's report on presentation led to the question, "Is Alzheimer's disease an adaptability disorder?" [15]. Could emotional impact and the response to it determine intellectual development, functioning and reserve and cause loss even of short-term recall in later life?

Early life effects are becoming increasingly recognised as a factor in later onset of disease [17] [18] and aging [9]. These could also determine intellectual development, functioning and reserve and cause loss, even of short-term recall, in later life, either through neuronal or vascular epigenetic developmental pathways that result in neurodegenerative or vascular insufficiency disease [8] [10] [12].

Biological (cellular, physiological and social) stress related environmental factors are recognisable and modifiable and therefore can be used in the prevention and treatment of disease. The recent Nobel Prize in Medicine was awarded to Elizabeth Blackburn and Colleagues who in collaborative studies showed that women exposed to stress have altered telomerase activity and shorter telomeres-in other words age faster [19], indicate that stress is an important factor in determining lifelong patterns of aging and or disease.

Wellness may therefore carry an adaptive advantage, whether this is physical, mental or emotional. Dementia syndromes focus on cognition and there is evidence that cognitive challenges may alter the course of the disease in animals experimentally placed in more environmentally stimulating conditions [20], whereas even in humans withdrawal has adverse cognitive function effects associated with changes in brain structure [21].

The focus of cognitive input has left the field of emotion free of challenge and purpose in terms of capacity and cause of memory loss. In this case report, the suggestion raised is that childhood memories do impact on memory, then and later, and suggests that unhappy memory results in memory block, which happened in this patient, that manifests in later adulthood with Alzheimer's disease. No family history of Alzheimer's disease was able to be obtained other than of siblings not known to have symptoms of disease, all of whom attended the boarding school, were also orphaned but each had different challenges and responded to their situation differently. Mrs. JF was also accosted by her holiday host to the extent that she threatened she would jump out of the window to avoid anything from happening.

Although anecdotal and unable to be scientifically proven by this case report alone, the suggestion is nevertheless an interesting one, as emotion and fond memories may be protective and ought to be encouraged. Feeling good about oneself and one's past helps one to develop an ethical awareness as well as cognitively, producing an interaction of effects that are adaptive and beneficial and which permit more space for random access memory as well as storage of memory and memory recovery, and at a cellular level regeneration and plasticity.

Response to the same situation could also result in schizophrenic syndromes as a result of withdrawal from a seemingly insensitive and rather crass world as perceived by the sufferer, whose condition is an adaptation, by 
withdrawing from the world completely. Similarly depression is, in the writer's view, the result of an "egocentric" world view [22] or of comparison. Having a negative self perception leads to blaming others, from which manipulation results [22]. On the other hand, feelings of unhappiness or happiness are a reflective state that flows from actual incidents. These may have impinged on the person's rights, with feelings of having been violated, that one feels one cannot do anything about. This leads to feeling alienated and without hope, which is why faith is so important for recovery from and overcoming such challenges. Parenting skills come into this as they determine who feels assured and who does not [23]. Clearly, orphaned children and fostered children were not included in that debate [23].

If happiness is a factor in later memory function, and emotional stability is conducive to memory function, prevention may be possible through ensuring greater adaptability, increased reserve capacity and by proactively removing the factors that impinge on memory function throughout growth and development and into old age, as in each period factors may increase or reduce susceptibility to or from memory loss and disease. Ensuring a person's rights and encouraging happiness, whether to live in one's own home instead of being placed are challenges modern medicine now has to regard as intrinsic to patient wellness and quality of life [24] [25].

Emotional factors may not only play a significant role during development and prenatally [9]. Emotion may be the last facet of humanity that remains within each of us, which is why it is first to develop and lasts, to the last gasp [26], until death do us part. Knowingly, emotional response affects how we regard people and their wishes [27]. Do we need to have cognitive function to be managed according to our wishes [21]? Or are emotional responses sufficient reason to have regard to our wishes, that were made known when we are able to cognitively give expression to them [20]? We respond with fear to people who show anger, but to those who are affectionate and friendly we respond with reciprocal warmth, understanding and love. Why does it not occur to us to respond to a person's state of happiness in the same way. Is it because it does not directly affect us? It ought to. Compassion is a virtue which defines humanity. It needs to be present in us to recognise that even those who cannot voice their opinion in cognitive terms, do still appreciate to be comforted and loved, and understood in terms that they find comforting and meaningful, i.e. according to their wishes, which is the cornerstone that defines "best interest" [24].

This issue has obvious significance for Guardianship and respect of rights of the individual under Guardianship, such as where they wish to be cared for, funds permitting that this can be arranged, if their request is to be cared for in their own home [22] [24] [25]. Asking the patient is an essential component of capacity assessment [28]-[30] and goal setting [24] [25] [31]. Using the Functional Mental State Measure (FMSM) [28]-[30] to assess mental capacity one obtains the person's own rating performance, which is compared to a health professional's assessment, using a simple, 1-7 rating score, based on the Functional Independence Measure (FIM) score [32]. The concordance or discordance of the scores is an indicator of capacity, which can also be an indicator of the need for treatment [28] [29].

The advantage of a functional mental capacity assessment is that it tests what the patient can do in terms of activities of daily living and their recognition of the need for any help personally or in domestic tasks or community activities such as shopping, and by asking questions as to where they wish to live, who with them or they with whom, and whether they would like a pet, and can take their medication or call for help if required and under what circumstances, and whether they need help to carry out activities or to appoint a power of Attorney or advocate. Capacity assessment tests their belief as to what they can do or think they can do. Mental capacity is demonstrated by how accurately they assess that. It has personal relevance, which adds meaning and therefore interest to take part in the assessment. Cognitive testing, on the other hand, is abstract and measures what the person cannot do. The advantage of a functional mental capacity assessment over cognitive assessment is not recognised enough nor followed through. Cognitive assessment, including neuropsychological assessments which do not test functional capacity, but which are requested by "stakeholders", whether family members or appointed Guardians, or Tribunals and Courts [22] [24] [33]-[38] and often detect impairment are used to restrict a person's choice and Rights. The FMSM was developed to address this [24] [28].

\section{Happiness and Advocacy}

Doctors must advocate for their patients' rights, even when they have capacity to choose. Legislative provision ensures that doctors who advocate to ensure their patient's rights are to be exonerated. It is therefore surprising that even though Legislative provision existed [Medical Treatment Act 1988], in Myers v Medical Practitioner's Board [VCSA 2007], it was ruled against Myers who advocated for his patient's right to go home from hospital 
once her condition was deemed palliative. It was her choice and for her part, her only option, to return home, with carer support, under the care of Dr. Myers, who was the only doctor she trusted, and to her husband. Given that unfortunate Court decision and the wrong it represents [21] [35], it is not surprising that the Australian Council of Health Care [ACHC] standards, in 2013, put in place requirements that patient rights be respected or hospitals who do not would lose their accreditation [39] [40].

This indicated an acceptance of standards that supported the view of the two senior Supreme Court judges who, on the basis that "findings of misconduct against a doctor are of some significance" granted leave to Appeal as the decisions below indicated "error and”, in their view, "wrong, were the decision to stand" [35]. The ACHC standard and guidelines [39] showed that the profession [40] and public [41] accepted what the Chief Justice did not, but which the Appeal Court Judges who granted leave did [35], as did the expert witnesses who testified before the Tribunal. They described Myers, as "a leader in the field”, "his intentions are pure, whereas I (the other specialist) acted with expediency to save my own backside at the expense of the patient's happiness” and "Dr. Myers goes beyond the call of duty for his patients". The Tribunal failed to take notice and sided with the Medical Board. In hindsight, and given the ACHC standards recently proposed [39] [40], it is clear that the Supreme Court of Appeal Judges, including the Chief Justice, M Warren, who decided the matter, also erred, though reference to the Medical Treatment Act 1988, which the Chief Justice chose to ignore, at the time, already indicated their “error and wrong” [22] [35]. Similarly, the High Court judges, Hayne J. and Crennan J., in failing to grant special leave to Appeal the remaining 10/53 allegations, all ten of which were prefaced on there being Elder Abuse, they, in my view, spawned this singular opportunity to prevent, or at least warn against committing, Elder Abuse in Australia.

As time would have it, the ACHC requirement [39] and call for inclusion to upgrade current practice [40] would show a correction was needed, and prove my view and actions, as veritable and correct, as Buchanan J. and Nettle J., in granting leave to appeal the Medical Board's, Tribunal's, Master of the Supreme Court's and Kaye, J., Supreme Court's decision, had done [35]. It was also against the Legislative provision as contained in the Medical Treatment Act 1988, the relevant Law in this case, which gives recognition to the patient's wishes and exonerates the doctor who advocates for his patient's rights to refuse treatment. Had her wish to go home, which was known to all at the time, been granted and her rights upheld, prior to the Tribunal decision that she be discharged home, as deemed palliative, it would have extended her period at home and her happiness. Keeping her there led to withdrawal, her refusal to eat, development of a leg ulcer and feelings of unhappiness. She desired familiar surroundings, proximity to her husband and his affection in their own home, where carers, she had employed to care for her, were to cook and clean, so that she and her husband could continue to live there together, as was their wish, to continue in their marriage of more than fifty years.

The President of the Medical Board, Dr. Joanna Flynn stated that "discharging the patient to a nursing home was acceptable”. As it was against the patient's wish, that view cannot be upheld. It is a view that caused the patient's unhappiness and which is in conflict with the Medical Treatment Act 1988, Law and Human Rights. The Supreme Court of Appeal decision is likewise a violation of Human Rights [42]. Both decisions are at odds with the ethical practice standards that have been upgraded and reflect the advised current standards of practice that now pertain [39]. Dr. Myers’ advocacy for his patients was noted by his peers and experts, to be, "beyond the call of duty", "ensuring his patient's happiness”, some four-teen years before these newly recognised standards

pertained, that "he is a leader in the field" who was ahead of his time. His advocacy and management is even more laudable, as it was in the face of opposition to his patient's wishes by a third party who complained to the Medical Board as she did not want her mother in law to go home, for selfish reasons. Indeed, in the preamble to the said Act, the Medical Treatment Act 1988 acknowledgement is made to the difficult circumstances doctors who advocate for their patients, may find themselves in. Persistence and endurance and the Tribunal's contemporaneous decision on the basis of the carer's testimony that the patient only trusted Dr. Myers, ensured the patient and her husband got their wish to being together in their own home, and her happiness, in achieving their wish and goal.

\section{Documentation of Happiness, As a Goal and for the Record}

Unjust and unfair are decisions in regard to appropriate management that fail to take into account contemporaneous reports of "happiness" by the patients themselves or about them by those caring for them at the time [22]. Failure to assess later complaints in that context, promotes maladjusted behaviour in notifiers [22], does not 
protect the public, is not in the patient's interest [41], and does not ensure medical services of a high standard or at all [22] [41].

Documentation of the patient's own admission of happiness as well as their own contemporaneous documentation and expressions describing their own happiness [22] [24] [25] [27], above all, reflects correct professional standards of ethical medical practice and management [2] [24]-[28][34] [36] [43] [44].

Contemporaneous documentation by a professional and independent third party serves to counter claims "of unhappiness", that psychiatrically disturbed or manipulative patients may claim, either in their own personal settings, in medico-legal claims or clinical settings [22]. The required standard of assessing "happiness" must be contemporaneous. Similarly, anything that provokes levels of unhappiness is to be noted at the time. They ought to be considered as abusive if they cause unhappiness to be voiced, noted or expressed, and where those factors, despite warning, or knowingly related to a person's unhappiness, are continued [22].

Assessment of this patient using the Functional Mental State Measurement (FMSM), as described above, [28]-[30], indicated that she retained capacity with good concordance of her own assessment and the examiner's and assessing her answers to lifestyle questions and personal choice with her husband's knowledge of them, and they concurred. She was able to recall her "unhappiness" and to reclaim her "happiness" now.

\section{Conclusion}

Ensuring a person's wishes are fulfilled, which is their "best interest” [22] [24] [25] [31] [43] [44], also referred to as social and psychological wellbeing [45], and which ensures their happiness, and which offsets disease [2] [7], offers new avenues of reflection and action that may prevent later development of Alzheimer's Disease. This approach may also serve as a useful standard to guide management of Elder persons, with and without Alzheimer's Disease, and who retain capacity. It may also be applied to the management of egocentric or maladjusted and or manipulative psychiatric patients. Thus, "happiness" may serve as the basis on which to formulate balanced assessments of different psycho-social situations in the patient's best interest, relevant goal setting [22] [24] [25] [27] and audits [31]. By doing so, we can understand the factors involved and that prevent and or delay mental illness and memory loss occurrence [1]-[4] [6] [9] [10] [14] [22], and assess treatment by obtaining direct answers and responses from patients [22] [27] [28], provided they are genuine and are not being manipulative [22].

\section{References}

[1] Snowdon, D.A., Greiner, L.H. and Markesbery, W.R. (2000) Linguistic Ability in Early Life and the Neuropathology of Alzheimer's Disease and Cerebrovascular Disease: Findings from the Nun Study. Annals of the New York Academy of Sciences, 903, 34-38. http://dx.doi.org/10.1111/j.1749-6632.2000.tb06347.x

[2] Danner, D., Snowdon, D. and Friesen, W. (2001) Positive Emotions in Early Life and Longevity: Findings from the Nun Study. Journal of Personality and Social Psychology, 80, 804-813. http://dx.doi.org/10.1037/0022-3514.80.5.804

[3] MRC Cognitive Function and Ageing Study, Yip, A.G., Brayne, C. and Matthews, F.E. (2006) Risk Factors for Incident Dementia in England and Wale: The Medical Research Council Cognitive Function and Ageing Study. A Population-Based Nested Case-Control Study. Age Ageing, 35, 154-160. http://dx.doi.org/10.1093/ageing/afj030

[4] Stern, Y. (2012) Cognitive Reserve in Ageing and Alzheimer’s Disease. Lancet Neurology, 11, 1006-1012. http://dx.doi.org/10.1016/S1474-4422(12)70191-6

[5] Myers, J.B. (2009) “Capillary Band Width”, the "Nail (Band) Sign”: A Clinical Marker of Microvascular Integrity, Inflammation, Cognition and Age. A Personal Viewpoint and Hypothesis. Journal of the Neurological Sciences, 283, 8690. Elsevier Publications, New York. http://dx.doi.org/10.1016/j.jns.2009.02.320

[6] Ngandu, T., Lehtisalo, J., Solomon, A., Levälahti, E., Ahtiluoto, S., et al. (2015) A 2 Year Multidomain Intervention of Diet, Exercise, Cognitive Training, and Vascular Risk Monitoring versus Control to Prevent Cognitive Decline in AtRisk Elderly People (FINGER): A Randomised Controlled Trial. Lancet. http://dx.doi.org/10.1016/S0140-6736(15)60461-5

[7] Myers, J.B. (2014) PM358 the Eco-Society or Eco-Social ${ }^{\odot}$ Environment and Heart Disease. A General Systems Approach. Global Heart, 9, e134. World Heart Federation's World Congress of Cardiology, 4-7 May 2014, Melbourne.

[8] Fraga, M.F. and Esteller, M. (2012) Epigenetics and Aging: The Targets and the Marks. Epigenetics, 8, 841-852.

[9] Qiu, A., Anh, T.T., Li, Y.H., et al. (2015) Prenatal Maternal Depression Alters Amygdala Functional Connectivity in 6-Month-Old Infants. Open. Translational Psychiatry, 5, e508. http://dx.doi.org/10.1038/tp.2015.3 
[10] Myers, J.B. (1982) Biochemical Response to Change in the Environment and the Nature of "Essential” Hypertension. Medical Hypotheses, 9, 241-257. http://dx.doi.org/10.1016/0306-9877(82)90154-2

[11] Patki, G., Solanki, N., Atrooz, F., Allam, F. and Salim, S. (2013) Depression, Anxiety-Like Behavior and Memory Impairment Are Associated with Increased Oxidative Stress and Inflammation in a Rat Model of Social Stress. Brain Research, 20, 1539, 73-86. http://dx.doi.org/10.1016/j.brainres.2013.09.033

[12] Myers, J.B. (2005) Infection, Periodontal Disease, Inflammation, Vascular (Capillary) Injury and Cognitive Decline with Ageing: An Hypothesis. Journal of the Neurological Sciences, 236, 518, 1650.

[13] Myers, J.B. (2015) Periodontal Disease-A Physician’s Viewpoint. In: Virdi, M.S., Ed., Emerging Trends in Oral Health Sciences and Dentistry, Chapter 29, Intech Publishers, 663-671.

http://www.intechopen.com/books/emerging-trends-in-oral-health-sciences-and-dentistry/periodontal-disease-a-physici an-s-viewpoint.

[14] Fernandes, M. (2011) The Influence of Background Context on Memory in Older Adults. Abstracts of the International Conference on Aging \& Cognition, Dortmund, 14-16 October 2010. Journal of Psychophysiology, 25, 6-46. www.ifado.de/AC2010/index.html.

[15] Myers, J.B. (2009) Is Alzheimer's Disease an Adaptability Disorder? Proceedings of the 6th International Congress on Vascular Dementia, Barcelona, 19-22 November 2009, Abstract p83. www.Kenes.com/vascular

[16] Myers, J.B. (2011) Microvascular Function and Cognition: Nail Changes and Memory Loss. Proceedings of the International Conference on Ageing and Cognition, Dortmund, 14-16 October 2010. Journal of Psychophysiology, 25, 1- 5. www.ifado.de/AC2010/index.html

[17] Portela, A. and Esteller, M. (2010) Epigenetic Modifications and Human Disease. Nature Biotechnology, 10, 10571068. http://dx.doi.org/10.1038/nbt.1685

[18] Gilbert, E.R. and Liu, D. (2012) Epigenetics: The Missing Link to Understanding $\beta$-Cell Dysfunction in the Pathogenesis of Type 2 Diabetes. Epigenetics, 7, 841-852. http://dx.doi:10.4161/epi.21238

[19] Epel, E.S., Blackburn, E.H., Lin, J., et al. (2004) Accelerated Telomere Shortening in Response to Life Stress. PNAS, 101, 17312-17315. http://dx.doi.org/10.1073/pnas.0407162101

[20] Baraldi, T., Schöwe, N.M., Balthazar, J., et al. (2013) Cognitive Stimulation during Lifetime and in the Aged Phase Improved Spatial Memory, and Altered Neuroplasticity and Cholinergic Markers of Mice. Experimental Gerontology, 48, 831-838. http://dx.doi.org/10.1016/j.exger.2013.05.055

[21] Brown IV, C.H., Coresh, J., Alonso, A., et al. (2015) Association of Hospitalization with Long-Term Cognitive and Brain MRI Changes in the ARIC Cohort. Neurology, 84, 1443-1453. http://dx.doi.org/10.1212/WNL.0000000000001439

[22] Myers, J. (2014) Medical Ethics: Context Is the Key Word. International Journal of Clinical Medicine, 5, 1030-1045.

[23] Brummelman, E., Thomaes, S., Nelemans, S.A., Orobio de Castro, B., Overbeek, G. and Bushman, B.J. (2015) Origins of Narcissism in Children. Proceedings of the National Academy of Sciences of the United States of America, 112, 3659-3662. http://dx.doi.org/10.1073/pnas.1420870112

[24] Myers, J.B. (2006) Ethics and Professional Medical Opinion and Guardianship and Administration Legislation. Internal Medicine Journal, 36, 540-541. http://dx.doi.org/10.1111/j.1445-5994.2006.01111.x

[25] Myers, J.B. (2007) "Duty to Care”, or, "Duty of Care” and the Goal of Medical Treatment. Internal Medicine Journal, 37, 211. http://dx.doi.org/10.1111/j.1445-5994.2006.01306.x

[26] Myers, J.B. (2010) Ars Moriendi-Ars Vivendi-The Art of Living Life to The Full. Proceedings of the ANZSPM (Australian and New Zealand Society of Palliative Medicine) Conference, Adelaide, 14-17 September 2010.

[27] Shell, L. (2015) The Picture of Happiness in Alzheimer’s Disease: Living a Life Congruent with Personal Values. Geriatric Nursing, 36, S26-S32.

[28] Myers, J.B. (2002) Dementia Diagnosis: Replacing a Conundrum with a Functional Mental Sate Measure (FMSM). 10th Annual Scientific Meeting of the Australasian Faculty of Rehabilitation Medicine AFRM (RACP) in Association with CONROD —Centre of National Research on Disability \& Rehabilitation Medicine, Brisbane, 7-10 May 2002.

[29] Myers, J.B. (2007) The Functional Mental State Measure (FMSM1) for Capacity Assessment. Proceedings of the 40th National Conference of the Australian Association of Gerontology, Adelaide, 21-23 November 2007. Australian Journal of Ageing, 26, A49.

[30] Myers, J.B. (2013) Cognitive Function or Functional Cognition? Use of the Functional Mental State Measure (FMSM) to Determine Capacity. Case Report. Proceedings of the 2nd International Conference on Aging \& Cognition, Dortmund, 25-27 April 2013. Journal of Psychophysiology, 55. www.ifado.de/AC2013/index.html.

[31] Myers, J.B. (2010) Clinical Indicators: The Role of Patient in Goal Setting, Evaluation and Ethical Practice. Internal Medicine Journal, 40, 244-246. http://dx.doi.org/10.1111/j.1445-5994.2009.02151.x 
[32] Hamilton, B.B., Laughlin, J.A., Fiedler, R.C. and Granger, C.V. (1994) Inter-Rater Reliability of the 7-Level Functional Independence Measure (FIM). Scandinavian Journal of Rehabilitation Medicine, 26, 115-119.

[33] Myers, J.B. (2010) Capacity and Cognition: Divergent or Convergent. Practical Significance: Respecting Function and Rights or Description and Abuse. Proceedings of the International Conference on Ageing and Cognition, Dortmund, 14-16 October 2010. www.ifado.de/AC2010/index.html.

[34] Myers, J.B. (2013) Is the Future Direction in Health About Bureaucratic Self Interest or Creativity, Professionalism and Wellbeing? Rights and Responsibility Must Replace Quality And Safety in Health Care. Proceedings of the RACP Future Directions in Health Congress, Perth, 26-29 May 2013. Internal Medicine Journal, 43, 1-55.

[35] (2007) Justice Buchanan and Justice Nettle. Supreme Court of Appeal. Leave Application. Myers vs Medical Practitioner's Board of Victoria. VSCA163.

[36] Myers, J.B. (2011) Elder Abuse Encountered in Private Geriatric Practice. Where Does the Buck Stop? Proceedings of the 9th Asia/Oceania Regional Congress of Gerontology and Geriatrics, Melbourne, 23-27 October 2011.

[37] Myers, J.B. (2011) Geriatric Assessment. What Really Counts-Abstract Testing or What Is Retained in Context? Proceedings of the 9th Asia/Oceania Regional Congress of Gerontology and Geriatrics, Melbourne, 23-27 October 2011.

[38] Myers, J.B. (2012) A System of Evaluated Decisions. Capacity Assessment: Who Can Decide? Proceedings of the 45th Annual Australian Association of Gerontology National Conference, Brisbane. 21-23 November 2012.

[39] EQuIP National (2013) Australian Council on Healthcare Standards.

[40] MacKee, N. (2013) Make Advanced Care Directives Routine. MJA Insights.

[41] (2014) Legislative Council Inquiry into Australian Health Profession Registration Agency (AHPRA).

[42] (2015) The Universal Declaration of Human Rights: Articles 6, 8, 10, 13.

[43] Myers, J.B. (2010) Protecting the Rights of the Aged and Individuals Referred for Health Care. Proceedings of the ANZSPM (Australian and New Zealand Society of Palliative Medicine) Conference, Adelaide, 14-17 September 2010.

[44] Myers, J.B. (2007) Submission to the House of Representatives Standing Committee on Legal and Constitutional Affairs Inquiry into Older People and the Law. LACA Reps., Parliament of the Commonwealth of Australia.

[45] (2005) Elder Abuse Prevention. Office of Senior Victorians. Consultation Paper. 